\title{
En búsqueda de los salvadoreños en los Estados Unidos: contextualizando los datos etnográficos
}

\section{Milton Ricardo Machuca*}

En este artículo presento una visión de conjunto de la literatura etnográfica sobre los salvadoreños en Estados Unidos. La migración salvadoreña a los Estados Unidos comienza a finales del siglo XIX, sin embargo los salvadoreños no llegan en masa a ese país hasta principios de la década de los ochenta, a principios de la guerra civil que duraría doce años (1980-1992). En las pasadas tres décadas, la literatura general sobre salvadoreños en Estados Unidos es extensa y cubre una amplia variedad de disciplinas. Muchos trabajos académicos estudian a los migrantes salvadoreños bajo la categoría de "centroamericanos". Con el notable incremento de la migración salvadoreña a los Estados Unidos a partir de 1980, se ha publicado un número significativo de etnografías sobre su experiencia migratoria en las pasadas dos décadas. En este artículo se discuten y comparan nueve de esos trabajos académicos. Estos trabajos tratan a los salvadoreños desde temas, tópicos y perspectivas particulares, los cuales incluyen inmigración y emigración, diáspora y transnacionalismo, cambios en relaciones de género, leyes migratorias estadounidenses y estatus migratorio, remesas y derecho al voto. A medida que los migrantes salvadoreños forjan nuevas redes de conexión e interacción social entre su país de origen y los Estados Unidos, los trabajos académicos buscan entender y teorizar sobre estos emergentes espacios transnacionales.

Palabras clave: El Salvador / Migración / Etnografía / Estados Unidos

Nos hemos convertido en un pueblo de emigrantes. El vice-presidente salvadoreño durante una conferencia en San Salvador en agosto del 2000 (Citado en Coutin, 2003, p. 523) 
La migración se ha convertido en la principal forma de participación de El Salvador en la globalización.

(PNUD, 2005, p. 6)

\section{Introducción ${ }^{1}$}

Una socióloga dominicana, amiga y mentora, me dijo una vez que "lo que El Salvador produce más es gente". Si bien su comentario no era completamente en serio, tampoco era inexacto. En efecto, aparte del café, la principal exportación de El Salvador (y con toda probabilidad igualmente cierto para el resto de países centroamericanos vecinos) ha sido su gente, en especial en su historia más reciente.

El Salvador es el país más pequeño de Latinoamérica con un área de 21,041 $\mathrm{km}^{2}$-más o menos del tamaño de New Hampshire, 23,227 km². Durante el siglo XX, progresivamente, El Salvador se convirtió también en el país más densamente poblado de Latinoamérica. Estimados recientes indican que en 2009, a una tasa de crecimiento natural del 2\%, su población alcanzó los 7.3 millones; en consecuencia, su densidad poblacional sigue siendo la más alta del continente: 349 personas por $\mathrm{km}^{2}$ o 903 personas por $\mathrm{m}^{2}$ (Population Reference Bureau, 2009)2. Alta densidad poblacional y recursos naturales limitados han sido las causas subyacentes de muchos de los problemas sociales, económicos y políticos de la nación. A lo largo de su historia el país ha visto una amplia variedad de alzamientos cíclicos organizados en particular por comunidades marginadas y excluidas de campesinos e indígenas (Woodward, 1988; Anderson, 1992).

Hasta la década de los setenta, para la gente en los Estados Unidos El Salvador no era más que un país poco conocido en algún rincón de Centroamérica. En la década de los ochenta, sin embargo, la coincidencia de factores sociales y políticos que precipitaron la guerra civil que duró 12 años, de 1980 a 1992, repetidamente sacó al país desde su proverbial anonimato a titulares de primera plana. La guerra civil salvadoreña fue una expresión de la desigual estructura económica en el país complicada por el contexto internacional más amplio de la Guerra Fría y la activa participación e influencia de los Estados Unidos. A finales de la década de los setenta y a lo largo de la de los ochenta, Centroamérica se convirtió en el escenario del capítulo final de la Guerra Fría. Esta situación afectó a todos los países en la región, particularmente a Guatemala, Nicaragua y El Salvador.

La guerra civil salvadoreña, el capítulo más oscuro y sangriento en la historia del país, sigue siendo el evento que definió la vida del pueblo salvadoreño contemporáneo. $\mathrm{Su}$ precio en muerte, violencia y éxodo fue muy alto. Como consecuencia, una característica significativa de El Salvador contemporáneo es que se ha convertido en

1 Este artículo fue originalmente publicado en inglés como "In Search of Salvadorans in the United States: Contextualizing the Ethnographic Record" en Urban Anthropology and Studies of Cultural Systems and World Economic Development. 39, (1-2) Spring/Summer 2010, 1-45. Por respeto a ese contexto original de publicación, a riesgo de sonar redudante o pedante, decidí respetar esa posicionalidad en mi traducción al castellano.

2 Por contraste, la densidad poblacional de New Hampshire a mediados del 2009 era de 57 personas por km² o 147 por $\mathrm{m}^{2}$. 
un país de emigrantes. No se niega que la migración salvadoreña existiera antes de la guerra, pero durante los años de la guerra civil subió a niveles nunca antes vistos. No obstante, la migración internacional salvadoreña no se detuvo cuando los acuerdos de paz fueron firmados en 1992 y la guerra concluyó oficialmente. Más aún, una maltrecha economía de post-guerra, una serie de desastrosas políticas económicas neoliberales implementadas en la década de los noventa por varias administraciones del partido de derecha Alianza Republicana Nacionalista (ARENA), un extendido clima de violencia e incertidumbre, un devastador huracán en 1998 y varios terremotos letales en el 2001, todo ello contribuyó a dar forma, estimular y sostener el proceso de migración salvadoreña iniciado más de una década antes y que se extendió ya entrado el siglo XXI (Winschuh, 1999; Córdova, 2005; PNUD, 2006).

Entender la trayectoria de los salvadoreños a los Estados Unidos como parte de la "Nueva Inmigración" post- $1965^{3}$, primero como residentes temporales y luego como comunidades reconocibles, presenta importantes problemas para los científicos sociales. Mi meta en este ensayo es responder a dos preguntas: primera, ¿cuál ha sido la experiencia de las comunidades salvadoreñas asentadas en los Estados Unidos en las pasadas tres décadas? Segunda, ¿cómo han abordado etnográficamente los científicos sociales el estudio de dichas comunidades?

Para responder a estas preguntas se condujo una revisión exhaustiva de los principales trabajos etnográficos sobre salvadoreños en los Estados Unidos ${ }^{4}$. Sin embargo, el lector debe tener en consideración las limitaciones del alcance de esta revisión de literatura. Limitaciones de tiempo impidieron discutir trabajos de académicos no estadounidenses o de trabajos escritos en castellano. No se incluyeron algunos trabajos no publicados porque sería difícil escoger una muestra representativa de tales publicaciones. De manera similar, si bien relacionados a la migración salvadoreña a los Estados Unidos, los trabajos académicos que tratan de las pandillas salvadoreñas fueron deliberadamente excluidos de este ensayo. Los estudios de pandillas salvadoreñas están abriendo fructíferas áreas de discusión con respecto a geografía vinculada y constructos culturales compartidos entre Estados Unidos y El Salvador. Los estudios de pandillas también demuestran la influencia que ejercen las políticas sociales, tales como la deportación criminal, en la determinación de la fisonomía de flujos transnacionales de población. Mi decisión para excluir el trabajo sobre pandillas obedece a que ésta es una situación política y etnográfica que requiere un tratamiento mucho más profundo y extenso del que

3 En Estados Unidos, "Nueva Immigración" y "Nuevos Immigrantes" se refiere usualmente a aquellos que llegaron después de que fuera aprobada la Ley de Inmigración y Nacionalidad de 1965. Se la conoce también como la Ley Hart-Celler porque fue propuesta por el representante democrático de Nueva York Emanuel Celler, co-patrocinada por el senador demócrata de Michigan Philip Hart y fuertemente apoyada por el senador demócrata de Massachussetts Ted Kennedy. Esta ley implementaba una serie de políticas que permitian una corriente migratoria mayor desde Latinoamérica y Asia (Ver Fuchs $\mathscr{E}$ Forbes, 1985; Daniels, 1990; Haines 8 Rosemblum, 1999; Waters $\mathcal{E}$ Ueda, 2007).

4 Una búsqueda exhaustiva de la literatura ubicó los estudios citados en este ensayo. Se hicieron busquedas en Anthropological Index Online, Anthropology Plus, Dissertation Abstracts, JSTOR, Web of Science, WorldCat. Las estrategias de búsqueda variaron dependiendo de la base de datos; en particular hubo variaciones en el gentilicio en inglés de la gente de El Salvador; el más común fue (El) Salvadoran, y menos frecuente (El) Salvadorean y (El) Salvadorian. A partir de los estudios primarios aparecieron otras fuentes. En resumen, se encontraron cerca de 100 trabajos publicados sobre salvadoreños en los Estados Unidos a través de las diferentes búsquedas. 
este ensayo permitiría ${ }^{5}$.

Los trabajos que se discuten en este ensayo dan una visión de conjunto de las etnografías estadounidenses publicadas sobre salvadoreños en los Estados Unidos desde 1979. A pesar de este "E.U.A.-centrismo", éstas son útiles para formular conclusiones sobre el conocimiento académico sobre la migración salvadoreña hacia Estados Unidos y sobre comunidades transnacionales en un mundo globalizado. Estos trabajos se enfocan en la migración salvadoreña desde temas, tópicos y perspectivas muy particulares, los cuales incluyen inmigración y emigración, diáspora y transnacionalismo, cambios en relaciones de género, cambios en relaciones generacionales, y status migratorio legal versus ilegal. Los académicos que se discuten aquí son predominantemente de Estados Unidos y sus trabajos están escritos en inglés. El trabajo concluye con algunas sugerencias para futura investigación.

\section{La migración salvadoreña hacia Estados Unidos}

La migración salvadoreña no es un fenómeno nuevo; varios académicos han estudiado la migración salvadoreña interna y dentro de Centroamérica (ver, por ejemplo, Sermeño Lima 1999). Del mismo modo, la migración salvadoreña específicamente hacia los Estados Unidos no es un fenómeno nuevo (ver, por ejemplo, Peterson, 1986; Menjívar, 1999; Smith, Shue, Vest \& Villarreal, 1999; Córdova, 2005; Wright \& Moody, 2005; Rodríguez, 2009). Sin embargo, antes de la década de los ochenta, la escala cualitativa y cuantitativa era mucho más pequeña que en años siguientes. En la búsqueda para entender los patrones migratorios salvadoreños hacia Estados Unidos, diferentes intelectuales han utilizado diferentes fechas y períodos. Por ejemplo, Peterson (1986, p. 11) coloca la migración salvadoreña significativa a los Estados Unidos tan temprano como en los sesenta; Montes Mozo y García Vásquez (1987, 1988) marcan su cronología desde 1941, dividiéndola en cuatro períodos desiguales. En un extenso y detallado reporte, el PNUD (2005, pp. 31-34) sitúa la génesis de la migración salvadoreña en los años veinte, dividiéndola en cuatro olas sucesivas. Por otro lado, Córdova (2005, pp. 60-68) la rastrea hasta 1870 y la divide en seis períodos. Si bien no hay consenso en las fechas de las primeras migraciones significativas, sí hay acuerdo en que cuantitativa y cualitativamente la migración internacional salvadoreña desde la década de los setenta ha alcanzado niveles y tenido un impacto nacional e internacional nunca antes visto.

El grueso de la migración salvadoreña en las últimas tres décadas ha sido hacia los Estados Unidos. Con respecto a los registros sobre migración internacional, Douglas Massey (1987) afirma que son de lo más contradictorios; él añade que la migración internacional "involucra dos culturas, dos sistemas administrativos, dos gobiernos, dos intereses políticos y, usualmente, dos idiomas". Los datos sobre migración a Estados Unidos no están libres de este padecimiento. El resultado se traduce en que los números están lejos de ser precisos, y en lugar de un un cálculo

5 El impacto de las pandillas no sólo en los Estados Unidos y en El Salvador, sino también en la región mesoamericana es un fenómeno complejo. Ha sido el enfoque de varios trabajos sociopolíticos y etnográficos - por ejemplo, Gómez y Vásquez (2001); Vigil (2002); Garland (2009); Narváez Gutiérrez (2002). Particularmente importante es el trabajo de Elana Zilberg (2004; 2007). 
exacto, dan solamente una idea aproximada de la magnitud del proceso. Números recientes muestran que a la mitad de la primera década del siglo XXI, cerca del $90 \%$ de los salvadoreños residentes en el extranjero vivían exclusivamente en Estados Unidos; menos del 6\% vivían en Canadá; cerca del 3\% en México y países centroamericanos vecinos ${ }^{6}$; menos de un $1 \%$ en Australia ${ }^{7}$ y menos de un $0.5 \%$ estaban desperdigados en el resto del mundo (PNUD 2005, pp. 34-35).

Antes de los años ochenta los salvadoreños emigraban hacia Estados Unidos pero en números comparativamente menores a los de tres décadas siguientes. Ciertamente, hay una carencia de estudios académicos que aborden la migración salvadoreña pre-guerra civil a Estados Unidos. Es más, la información disponible es dispersa, incompleta o anecdótica. Córdova, por ejemplo, indica que el otrora Servicio de Migración y Naturalización (conocido como INS por sus siglas en inglés $)^{8}$ "solamente comenzó a llevar registros detallados de las migraciones centroamericanas después de 1932” (2005, p. 60). En octubre de 1976 ocurrió un cambio: el INS empezó a "mantener registros separados sobre los números de salvadoreños capturados que entraban [ilegalmente] a los Estados Unidos. Antes de esa fecha, los salvadoreños capturados se incluían en la categoría miscelánea otros del hemisferio occidental [Other Western Hemisphere]" (Stanley, 1987, p. 134). A pesar de esta "mejoría", la presencia salvadoreña en los Estados Unidos de mediados de los setenta a principios de los ochenta sería difícil de establecer; la cuenta no es más que un indicador indirecto pues los registros muestran solamente el número de salvadoreños capturados y deportados por el INS, y no aquellos que no fueron ni capturados ni deportados.

En un reporte del censo estadounidense, Peterson (1986, p. viii) indica que desde finales de la década de los setenta, en medio de la progresiva inestabilidad social en Centroamérica, el creciente interés en la migración dentro y fuera de la región por parte de los gobiernos nacionales, las organizaciones humanitarias y los académicos, había llamado la atención sobre un enorme incremento en el volumen de la migración anual neta desde Guatemala, El Salvador y Nicaragua hasta 15 veces más que niveles previos. Claramente, el abrupto y medible influjo de inmigrantes salvadoreños no

6 Inmigrantes salvadoreños huyeron a paises centroamericanos vecinos durante la guera civil y se asentaron en Belice (Palacio, 1985), Nicaragua (Morel, 1992) y Costa Rica (Quizar, 1998; Hayden, 2003; Basok, 1993).

7 El censo australiano de población y vivienda en el 2006 indicaba que 6,874 salvadoreños residian en ese país. El porcentaje más alto se concentraba en Melbourne (32\%), seguido por Brisbane (21\%) y Sidney (18\%) (Australian Bureau of Statistics, 2009).

8 El otrora INS fue creado en 1870. Era ampliamente conocido por su inefectivada, especialmente después de las controversias surgidas después del 11 de septiembre de 2001. En marzo de 2003, después de que la Ley de Seguridad Interior (Homeland Security Act) de 2002 entrara en vigor, las funciones del INS se pasaron a tres diferentes agencias dentro del recientemente creado Departamento de Seguridad Interior (Department of Homeland Security o DHS). La administración de servicios de migración -que incluyen residencia permanente, naturalización, asilo político y otros- pasó a ser responsabilidad de la Oficina de Servicios de Migración y Ciudadania (Bureau of Citizenship and Immigration Services o BCIS), la cual existió por un breve periodo antes de cambiar a su nombre actual, Servicios Estadounidenses de Migración y Ciudadania (U.S. Citizenship and Immigration Services o USCIS). Las funciones investigativas y de aplicación de la ley (incluyendo investigaciones, deportaciones e inteligencia) se le asignaron a los investigadores aduaneros (U.S. Customs investigators), al Servicio Federal de Protección (Federal Protective Service) y al Servicio Federal de Policía Aérea (Federal Air Marshal Service), las que se combinaron para crear el U.S. Immigration and Customs Enforcement (ICE). Las funciones de vigilancia fronteriza del INS, que incluian la Patrulla Fronteriza (Border Patrol) junto a los inspectores del INS, se combinaron con las de los inspectores de aduanas (U.S. Customs Inspectors) en la recientemente creada U.S. Customs and Border Protection (CBP) (http:// purl.access.gpo.gov/GPO/LPS18952). 
pasó desapercibido por las agencias gubernamentales estadounidenses (INS, Censo, etc.) y por los académicos; no obstante, es difícil estimar cuántos inmigrantes había, ya que su número depende de quién hace la cuenta y de la metodología aplicada, lo que ha resultado en un cálculo inferior de porciones significativas de la población? . Peterson (1986) dice que el censo poblacional estadounidense de 1980 enumeraba 73,000 salvadoreños, si bien no indica las áreas geográficas de asentamiento o status legal; Restrepo, trabajando con datos corregidos y mejorados, calcula 94,447 salvadoreños en 1980 (2004, p. 9). Hacia el final de la década de los ochenta, Montes Mozo y García Vásquez revelaron un sorprendente estimado "de aproximadamente un millón de salvadoreños residiendo en los Estados Unidos” (1988, p. 6).

Mil más, mil menos, la realidad es que la guerra civil en El Salvador generó un éxodo hacia Estados Unidos ${ }^{10}$. Los números actuales estiman entre 2.0 y 2.7 millones de salvadoreños residentes en Estados Unidos. En los albores del siglo XXI, la población latina total es ahora el grupo minoritario más grande en los Estados Unidos. Mexicanos, puertorriqueños y cubanos respectivamente todavía son la primera, segunda y tercera comunidad más grande de latinos según el país de origen; para 1990 los salvadoreños se convirtieron en la cuarta comunidad de latinos más grande según el país de origen (Restrepo, 2004). Sin embargo, este orden ha variado en los últimos diez años, disputándoselo con dominicanos y colombianos. Aún así, en menos de tres décadas los salvadoreños se han convertido en uno de los grupos latinos de más rápido crecimiento; la población salvadoreña es el grupo más grande de origen centroamericano, ciertamente una minoría en expansión (Wright \& Moody, 2005).

Dependiendo cada vez más de las redes sociales existentes -en expansión o ya maduras-, los salvadoreños (como cualquier otro grupo inmigrante) han establecido áreas distintivas de asentamiento en muchas ciudades y zonas suburbanas de Estados Unidos. Tradicionalmente se han asentado en estados tales como California (particularmente en el Gran Los Ángeles ${ }^{11}$ y el Gran San Francisco), Texas (Houston), Nueva York (Ciudad de Nueva y Long Island), Washington, D.C., Maryland y Virginia; en la actualidad están asentándose en estados "no-tradicionales" tales como Florida, Nevada (especialmente Las Vegas), Carolina del Norte y Georgia. Los salvadoreños hoy están dispersos en todos los Estados Unidos (Córdova, 2005; Wright \& Moody, 2005).

9 Mientras que el Censo de los Estados Unidos no permitió una identificación directas de los salvadoreños a lo largo de la década de los ochenta en la pregunta sobre "origen hispano", sí suministró otros acercamientos a través de los archivos resumen en cinta (Summary Tape Files o STF) y los microdatos de uso público (Public Use Microdata o PUM) (ver Logan, Zhang Ë Alba, 2000).

10El PNUD indica que, de acuerdo a cifras de la oficina del Censo de Estados Unidos, se estima que 0.2\% (cerca de 5,000 personas) de un total de 2.5 millones de la población vivían en Estados Unidos en 1960; esta cifra se duplica al 0.4\% (cerca de 14,400) de un total de 3.6 millones de población en 1970; se quintuplica al 2.1\% (cerca de 96,600) de un total de 4.6 millones de población en 1980; y luego brinca a un 9.1\% (cerca de 464,100) de un total de 5.1 millones de población en 1990. En 2000, los estimados muestran cifras tan bajas como 10.5\% (cerca 651,000) y tan altas como 40\% (cerca de 2.5 millones) de 6.2 millones. Para el 2005 la diáspora salvadoreña se estima en un 28\% (cerca de 2.6 millones) de un total de una población de 9.4 (PNUD, 2005, pp. 35-40).

11 Tradicionalmente, California ha sido el punto de destino para los inmigrantes salvadoreños; aproximadamente la mitad de los salvadoreños en los Estados Unidos viven alli. De hecho, el segundo grupo hispanohablante más grande en el estado, después de los mexicanos, son los salvadoreños. Cerca de la mitad vive en el Gran Los Angeles, el cual se ha convertido en el hogar del grupo más grande de salvadoreños, la segunda ciudad más grande después de San Salvador, la capital de El Salvador (Baker-Cristales, 2004, p. 4). 
Llegar a los Estados Unidos no ha sido fácil; establecerse en el país no ha estado libre de conflictos y de contradicciones. En la década de los ochenta, durante el período de creciente violencia a causa de la guerra civil, los salvadoreños huyeron en masa de su país. Obtener una visa para los Estados Unidos tomaba tiempo y gradualmente se hizo más y más difícil; aquellos salvadoreños que la pudieron conseguir (usualmente de turista) se quedaron después de que ésta expiró. Quienes no pudieron obtener una visa entraron al país sin autorización, usualmente cruzando la frontera ayudados por coyotes, después de una larga jornada por Guatemala y México. Caldeados debates surgieron alrededor de las políticas estadounidenses disputando si era una migración política o económica, en su mayor parte exacerbada por el apoyo oficial del gobierno estadounidense para el gobierno salvadoreño. Los que solicitaron asilo político se dieron cuenta rápidamente de que, independientemente de la evidencia, el gobierno estadounidense por los general no los consideraba como refugiados políticos sino como "inmigrantes económicos en busca de mejores oportunidades como cualesquiera otros inmigrantes", haciéndolo por tanto sujetos de deportación, sin consideración alguna de su bien fundamentado miedo a la persecución de ser enviados de regreso (Hamilton \& Chinchilla, 2001, p. 134). Fue una instancia de la ideología estadounidense de la Guerra Fría que prevalecía sobre la racionalidad o la sensibilidad, la que veía el mundo solamente en blanco y negro: refugiados que huían del comunismo calificaban, no así refugiados que huían de regímenes autoritarios. Hamilton y Chinchilla (2001, p. 135) concisamente resumen así la situación:

A diferencia de los inmigrantes de países comunistas considerados como enemigos de Estados Unidos, los salvadoreños y los guatemaltecos huían de gobiernos que estaban recibiendo, o habían recibido, ayuda económica y militar de Estados Unidos a cambio de su "alianza en la lucha contra el comunismo". Dadas estas consideraciones, incluso la evidencia dramática de persecución individual era raramente suficiente para otorgar asilo político ante jueces inclinados a tomar decisiones en materia migratoria consonantes con las políticas del departamento de estado durante las administraciones Reagan y Bush.

Estas acciones oficiales chocaron con mucha crítica y resistencia: el Movimiento Santuario representó quizás el esfuerzo más emblemático y extendido "para hacer que el pueblo estadounidense cayera en la cuenta de la guerra y la situación de derechos humanos en la región y la apremiante situación de los inmigrantes centroamericanos" (Hamilton \& Chinchilla, 2001, p. 144-147; ver también Coutin, 1995 y Rader, 1999). A través de los años, sin embargo, algunos eventos políticos y legales abrieron la puerta a ciertas políticas que le permitieron a los salvadoreños documentación legal a corto plazo y/o a un estatus más permanente en el país, a saber, la ley de reforma de inmigración de 1986 (conocida como IRCA por sus siglas en inglés), el status temporal protegido (conocido como TPS por sus siglas en inglés) y la partida obligatoria extendida (conocida como DED por sus siglas en inglés), ambas en la década de los noventa, el estatus ABC de 1991, y la ley de asistencia centroamericana y de ajuste nicaragüense de 1997 (conocida como NACARA por 
sus siglas en inglés) (Coutin, 2000, 2007; Córdova, 2005). El cambio en el proceso de las políticas ha tomado su tiempo. Mientrastanto, a pesar de los desafíos legales que enfrentan, el número de salvadoreños autorizados para vivir y trabajar en el país ha crecido significativamente, y un número considerable ha optado por la ciudadanía estadounidense. No obstante, muchos académicos sostienen que numerosos salvadoreños en los Estados Unidos carecen de documentos legales a largo plazo y que cerca de la mitad de ellos permanecen indocumentados, lo cual, de ser cierto, convierte a los salvadoreños en el mayor grupo indocumentado por país de origen en los Estados Unidos (Menjívar, 2000; Coutin, 2000; Baker-Cristales, 2004, 2008). Sea este el caso o no, es controversial porque es difícil obtener datos exactos sobre una población que ha sido empujada por las leyes migratorias estadounidense a una vida de exclusión y de marginación (ver Córdova, 2005, p. 72 y Baker-Cristales, 2008).

Casi tres décadas después del inicio de su inmigración a los Estados Unidos, los salvadoreños se han convertido en una comunidad transnacional en un mundo post industrial y globalizado. Por medio de una serie de procesos simultáneos han forjado y sostenido relaciones sociales multifacéticas que los vinculan a El Salvador y a los Estados Unidos (Basch, Glick Schiller \& Szanton Blanc, 1994, p. 7). Estos procesos han afectado a los salvadoreños en los Estados Unidos y en otros sitios a nivel político, cultural, ideológico y social. Tal como Baker-Cristales concisamente lo expresa, la diáspora salvadoreña "mantiene una presencia única en el imaginario [salvadoreño] nacional como una antítesis para construcciones de identidad nacional, como el proveedor invisible que sostiene la economía con remesas y en el sector político es un significativo sector del electorado, aunque privado de sus derechos" (Baker-Cristales, 2008, p. 349).

Económicamente hablando, El Salvador contemporáneo es extremadamente dependiente delas remesas de su población transnacional. Estas remesas-transferencias de dinero de inmigrantes salvadoreños que trabajan en los Estados Unidos a sus familias en El Salvador-siguen siendo una de las principales fuentes de ingreso externo y ayudan tremendamente a mantener a flote la economía salvadoreña ${ }^{12}$. Las remesas han sostenido la economía de la post-guerra civil salvadoreña. A medida que el número de inmigrantes salvadoreños aumentó, así lo hicieron las remesas. $\mathrm{Su}$ impacto es evidente; en 1978, estas sumas representaban el 8\% del total del producto nacional bruto (PNB); en contraste, el $81 \%$ venía de exportaciones agrícolas tradicionales. En el 2004, la proporción se invirtió completamente: las remesas representaban el 70\% del total del $\mathrm{PNB}$, mientras que las exportaciones agrícolas tradicionales representaban solamente el 5\% (PNUD, 2005). En la última década las remesas aumentaron continuamente y alcanzaron, de acuerdo al Banco Central de Reserva de El Salvador, una cifra sin precedentes de $\$ 3.8$ billones. Las remesas son en efecto una fuente vital del ingreso nacional salvadoreño y constituyen más del 18\% del producto interno bruto (PIB). Las encuestas muestran que un estimado

12 El impacto económico que los salvadoreños han tenido con sus envíos de dinero es claro (por ejemplo ver, García Vázquez, 1994, 1996; PNUD, 2005, 2006). Las fuentes no indican que éste sea el caso para los salvadoreños que viven en países vecinos tales como Nicaragua, Guatemala o Costa Rica, ni tampoco para aquellos que emigraron a Australia, Sur América o Europa. 
de 22.3\% de familias salvadoreñas recibe remesas (PNUD, 2005). En el período después de la crisis económica mundial, las remesas todavía se mantienen como la fuente de ingresos más importante para el país. Los anteriores gobiernos de derecha tenían lazos estrechos con la administración Bush. El número de salvadoreños indocumentados que residen en los Estados Unidos y el monto de remesas que ellos envían a El Salvador llevó a los presidentes salvadoreños Flores y Saca (las dos previas administraciones del partido de derecha ARENA) a hacer frecuentes viajes a Washington para solicitar a la administración Bush que no aplicara una deportación a gran escala de inmigrantes salvadoreños indocumentados, so pretexto que significaría una catástrofe económica para El Salvador. La respuesta de la administración Bush fue una política implícita de no-deportación y el otorgamiento de documentos legales a corto plazo a cambio del apoyo incondicional a las políticas estadounidenses, lo cual es evidente, por ejemplo, en el apoyo político y militar que le dieron a la ocupación de Irak en el 2003: el Salvador desplegó 389 soldados en agosto del $2003^{13}$.

Cultural e ideológicamente, los salvadoreños que viven en Estados Unidos también han tenido un impacto en el imaginario social de su país. Dos procesos ilustran este punto: el discurso gubernamental de el hermano lejano y el Departamento 15. Primero, en El Salvador de la post-guerra civil, el estado desarrolló un discurso alrededor de el hermano lejano ${ }^{14}$, en un esfuerzo para reincorporar a los emigrantes salvadoreños como parte del imaginario social salvadoreño, y para simultáneamente legitimar el proyecto económico estatal y para calmar cualquier tensión que pudiera surgir por parte de los emigrantes salvadoreños dada su inelegibilidad para votar en las elecciones salvadoreñas a menos que estuvieran físicamente presentes en el país (Landolt, 2003; Baker-Cristales, 2008). Baste decir que este discurso no fue bien recibido como metáfora dado su tono paternalista; las autoridades salvadoreñas han descontinuado su uso, si bien el monumento dedicado a el hermano lejano sigue de pie en la intersección de dos importante vías en San Salvador. Segundo, los medios de comunicación salvadoreños han denominado a los Estados Unidos como el Departamento 15, lo cual identifica a la diáspora salvadoreña como el décimo quinto departamento del país, además de los 14 departamentos dentro del territorio nacional (Rodríguez, 2009, pp. 170-194; Booth, Wade \& Walker, 2006, pp. 193. $194)^{15}$.

Políticamente, los salvadoreños que viven en los Estados Unidos han tenido un existencia a medias; como Baker-Cristales indica, los inmigrantes salvadoreños han sido excluidos de la participación formal en la política nacional

\footnotetext{
13 El Salvador, Nicaragua, Honduras y República Dominicana fueron los únicos países latinoamericanos que enviaron tropas para esta invasión de Irak.

14 Llama la atención que la expresión el hermano lejano haya resistido una traducción unívoca al inglés. Por ejemplo, Landolt, Autler y Baire lo traducen como the distant migrant-brother (1999, p. 293), Baker-Cristales como the distant brother (2004) o the long-lost brother (2008: 355) y Rodríguez como the distant relatives (2009). En mi artículo en inglés utilicé the faraway brother.

15En enero del 2000, bajo la previa administración de derecha del partido ARENA y la presidencia de Francisco Flores, el ministerio de relaciones exteriores salvadoreño legitimó este concepto de Departamento 15 al crear una nueva oficina especificamente designada para comunicarse con los salvadoreños que viven en el extranjero, la Dirección General de Atención a la Comunidad en el Exterior (DGACE), y con ella el puesto de vice-ministro para los salvadoreños que viven en el extranjero. Bajo la nueva administración de iziquierda del FMLN la oficina sigue operando y se ha nombrado un nuevo vice-ministro.
} 
en El Salvador y en los Estados Unidos, a pesar de "su importancia como actores políticos transnacionales por medio de la creciente dependencia de El Salvador en las remesas de migrantes" (Baker-Cristales, 2008, p. 349). Esta situación jugó un papel importante en los resultados de las elecciones presidenciales de 2009; los candidatos se dirigieron a las comunidades salvadoreñas en Estados Unidos (y hasta las visitaron) buscando una influencia indirecta sobre sus parientes en El Salvador. El derecho de los salvadoreños en el extranjero a ser reconocidos como una fuerza política y no sólo como una fuente de ingresos es un tópico que espera ser resuelto; si la actual administración de izquierda del FMLN lo resuelve, añadirá una nueva dimensión a la transnacionalización de El Salvador.

\section{Salvadoreños en los Estados Unidos: Estudios iniciales}

Durante la década de los ochenta, a medida que la escala de la migración centroamericana en general y la salvadoreña en particular progresivamente aumentaba, la mayoría de los investigadores durante este período (1) incorporaron el estudio de la inmigración salvadoreña dentro de la investigación sobre inmigración centroamericana ${ }^{16} \mathrm{y} / \mathrm{o}(2)$ intentaron discernir si estos flujos de inmigrantes eran o no estrictamente de naturaleza económica (como las fuentes oficiales estadounidenses enfatizaban), política (como la realidad de la guerra civil indicaba), o una mezcla de ambas (Menjívar, 1994). Dos estudios son los más importantes durante este período inicial de trabajo académico sobre salvadoreños en los Estados Unidos. Ambos trabajos se enfocaban en la dinámica de la migración salvadoreña a los Estados Unidos: el reporte del politólogo Guy Poitras sobre migración de retorno, publicado primero como una versión corta (1980a) y luego como una más larga (1980b) y el estudio de los sociólogos Segundo Montes Mozo y José García Vásquez, en ese momento el estudio exploratorio más grande sobre salvadoreños en los Estados Unidos, publicado primero en castellano (1987) y más tarde en inglés (1988). Estos estudios iniciales se preocupaban por establecer cuántos salvadoreños había y en qué parte de Estados Unidos estaban viviendo. En general ambos estudios se basaban primordialmente en métodos cuantitativos y menos en métodos cualitativos; los dos reunieron sus datos principalmente a través de encuestas, datos gubernamentales y entrevistas estructuradas. No eran estudios etnográficos per se sobre salvadoreños en los Estados Unidos. Dadas sus diferencias de enfoque, los discuto por separado.

\subsection{El Reporte Poitras}

In 1979, Guy Poitras completó un estudio financiado por la USAID: International Migration to the United States from Costa Rica and El Salvador, un análisis preliminar corto que fue publicado en abril de 1980, y The United States Experience of Return

16Cualquiera que tuviera alguna familiaridad con América Central como región, aunque fuera superficialmente, reconocería de inmediato que, a pesar de las similitudes en historia y lenguaje compartidos, hay obvias e incluso notables diferencias entre los cinco pueblos de las naciones centroamericanas. Además, en términos de procesos migratorios y de números, cada pais tiene un muy diferente historial de inmigración a los Estados Unidos. Con todo, el grueso del trabajo académico ha tendido a tratar a los centroamericanos como un grupo homogéneo. 
Migrants from Costa Rica and El Salvador, una versión más extensa y completa que fue publicada en agosto del mismo año. Este estudio descriptivo y cuantitativo se basó en las respuestas a 573 cuestionarios de una muestra de 314 costarricenses y 259 salvadoreños inmigrantes que regresaron. Es decir, personas que trabajaron en Estados Unidos y regresaron a sus países de origen, en un esfuerzo por obtener datos de grupos que no fueran mexicanos $(1980 \mathrm{a}, \mathrm{b})^{17}$.

Poitras reconoce que los salvadoreños y los costarricenses estaban incluidos en el estudio por razones fundamentalmente logísticas, a saber, financiamiento, contactos locales e información disponible (1980a, p. 5; 1980b, p. 5). El criterio de selección dentro de cada muestra incluía edad al momento de la entrevista (al menos 18 años), duración de la estadía en Estados Unidos (al menos un mes), número de viajes a los Estados Unidos (al menos uno) dentro del período 19691979. La muestra incluía más hombres que mujeres, entre 20 y 40 años de edad, en su mayoría solteros. Además, una de las metas del estudio era establecer una línea de base de comparación para estudios futuros; sin embargo, hay un problema metodológico con este estudio: su énfasis en la migración de retorno. Poitras trabaja bajo la suposición de que la migración salvadoreña y costarricense a los Estados Unidos, si bien empujada por factores económicos, es una migración circular y temporal (aunque no de temporada o de estación). Consecuentemente, en su afán por estudiar la migración internacional por medio de los migrantes de retorno y "no aquellos que se consideran a sí mismos como residentes permanentes de los Estados Unidos" (1980a, p. 3) Poitras incorrectamente concluye que "muy pocos de estos inmigrantes tendrán un efecto directo y duradero en la economía de los Estados Unidos en el futuro. Ellos no están interesados en trabajo permanente en Estados Unidos” (1980b). Quizás, al momento del estudio de Poitras, aquellos salvadoreños y costarricenses incluidos en la encuesta no estaban interesados en regresar a los Estados Unidos; sin embargo, como veremos más adelante, ese no sería el caso para la migración salvadoreña en los siguientes cinco años. Y aún así, Poitras indica que la migración centroamericana "seguirá [siendo importante] en la década de los ochenta” (1980a, p. 1). Por cierto, en un momento cuando la violencia en El Salvador estaba escalando y el país estaba al borde del conflicto armado, él destacó, de manera ominosa, la importancia de su estudio: "especialmente si los eventos en El Salvador demuestran ser tan importantes como para afectar la migración internacional desde ese país" (1980a, p. 4).

El estudio de Poitras también subrayaba tres tendencias que adquirirían relevancia en el futuro inmediato de la migración salvadoreña a los Estados Unidos: primera, en cuanto a su estatus migratorio, sus hallazgos indicaban que, comparados con los costarricenses, los salvadoreños eran "más propensos a depender de traficantes de personas y a una entrada indocumentada”. Él observaba que si bien

\footnotetext{
17 En su estudio, Poitras estaba interesado en "residentes temporales" más que en "establecidos" si bien él no utilizó esta terminología. El entendimiento convencional de la inmigración distinguía entre "residentes temporales" y "establecidos". En esta dicotomía, los primeros van a otro país por un breve periodo, mientras que los segundos buscan quedarse en el país de destino (ver, por ejemplo, Chávez, 1988; Cornelius, 1992). La más reciente investigación sobre inmigración, con su enfásis en el transnacionalismo, ha desafiado esta dicotomía. En un mundo globalizado, nuevas tecnologías permiten a los inmigrantes mantener relaciones y orientar sus acciones hacía su país de destino y su país de origen casi de manera simultánea. El espacio ya no es una limitación.
} 
el $81 \%$ de los que respondieron a la encuesta indicaban haber logrado alguna forma de "entrada legal", esta legalidad de entrada no les impedía que a la larga trabajaran ilegalmente (1980b, pp. 33-50). Segunda, con respecto a las áreas geográficas de asentamiento, los salvadoreños de la muestra del estudio de Poitras se habían establecido y trabajaban principalmente en California (52\%), seguido por Nueva York (19.5\%), Florida (8.9\%) y Texas (3.5\%) (1980b, p. 83). Tercera, Poitras indicaba que la meta de los migrantes era "repatriar tanto efectivo y bienes como pudieran a sus países de origen". Esta "repatriación de entradas" o "ingreso repatriado", como él lo llamaba, presagia una de las características más sobresaliente de los migrantes salvadoreños a los Estados Unidos, la contribución a la economía de su patria a través de las remesas (Poitras, 1980a, pp. 98-102; 1980b, pp. 94-97).

\subsection{Una visión desde el sur: El reporte de Montes Mozo y García Vásquez}

Los sociólogos salvadoreños Segundo Montes Mozo ${ }^{18}$ y Juan José García Vázquez ${ }^{19}$ fueron los primeros académicos en examinar los factores fundamentales sobre la migración salvadoreña a los Estados Unidos. El Salvador 1987: Salvadoreños refugiados en los Estados Unidos, el extenso y completo estudio original en castellano fue publicado en 1987; un año más tarde, Salvadorean Migration to The United States: An Exploratory Study, una versión resumida y compendiosa fue publicada en inglés. Cuando se publicó, representaba el análisis más exhaustivo a la fecha sobre migración salvadoreña a los Estados Unidos; presentaba un coherente y lúcido análisis las razones económicas, políticas y personales para esa migración salvadoreña, oponiéndose por tanto a las pretensiones por parte del gobierno estadounidense de que los inmigrantes salvadoreños eran solamente refugiados económicos quienes, en consecuencia, no calificaban para asilo político. El estudio de Montes Mozo y García Vásquez incluía datos reunidos a través de tres encuestas y de entrevistas detalladas en El Salvador (a 2,121 familias que tenían algún pariente en Estados Unidos) y en los mismos Estados Unidos (a 1,350 inmigrantes). Sus hallazgos primariamente cuantificaban y en menor grado calificaban un fenómeno que no era sorprendente pero que sorprendió a muchos. El hallazgo más importante era el cálculo de que al menos un millón de salvadoreños ya estaban viviendo en Estados Unidos, con altas concentraciones en California (Gran Los Ángeles), Washington, D.C. y Nueva York (en la ciudad de Nueva York y en Long Island). El estudio también estimaba que tres cuartos de los migrantes salvadoreños llegaron en 1979 cuando la guerra civil recién comenzaba. En sus respuestas, el 36\% indicaba que había emigrado por razones económicas, el $28.5 \%$ por razones políticas y el $20 \%$ por ambas. Revelaba que la

18Montes Mozo era sacerdote jesuita. Fue un escritor prolifico; el cuerpo de su trabajo es muy extenso. Si embargo, escribió principalmente en castellano y sólo algunos de sus trabajos han sido traducidos al inglés. Fue el fundador y director del Instituto de Derechos Humanos de la Universidad Centroamericana (IDHUCA) en San Salvador, El Salvador. La publiación de su investigación sobre migrantes salvadoreños a los Estados Unidos, los salvadoreños desplazados internamente y los refugiados salvadoreños en Honduras, le dieron a conocer internacionalmente. El 16 de noviembre de 1989, Montes Mozo, cinco jesuitas más, su empleada doméstica y la hija de ésta fueron asesinados por el ejército salvadoreño en el campus de la Universidad Centroamericana (UCA) en San Salvador, El Salvador.

19Bajo la actual administración del partido FMLN y la presidencia de Mauricio Funes, García Vasquez fue recientemente nombrado como vice-ministro de los salvadoreños residentes en el extranjero. 
situación legal salvadoreña en Estados Unidos era muy frágil y tenue: "apenas un tercio de los emigrantes goza de estatus legal, mientras que un quinto está en proceso de legalizar su estatus" (1987:19). En general, la muestra indicaba que la escolaridad de los inmigrantes salvadoreños era mayor que la media salvadoreña ( 8.7 versus 6 años), que eran jóvenes (24.8 años en promedio) y en su mayoría hombres (58\% de la muestra total); dos tercios estaban empleados y sus remesas (un promedio de $\$ 113$ al mes) eran la fuente más grande del ingreso externo de El Salvador de $\$ 1.3$ billones (la ayuda económica del gobierno estadounidense y las exportaciones de café eran las otras dos), por tanto manteniendo a flote la descalabrada economía salvadoreña en medio de una guerra civil financiada por Estados Unidos ${ }^{20}$ (Montes Mozo \& García Vásquez, 1987).

Otro descubrimiento inesperado de su estudio fue el impacto que las remesas de estos inmigrantes tenían sobre las comunidades en El Salvador. Su descripción de dos pueblos salvadoreños dependientes de las remesas, Intipucá, en el departamento de La Unión en el oriente, y Casitas, en el departamento de Santa Ana en el occidente, subraya una tendencia que habría de convertirse en una característica de la sociedad salvadoreña: el creciente impacto de las remesas en la economía salvadoreña. Gracias a las remesas los más olvidados y remotos cantones y pueblos, y muchas familias pobres en áreas urbanas, disfrutarían de la prosperidad y el beneficio del dinero mandado por sus familiares en el extranjero. Montes Mozo y García Vásquez llamaron la atención a la curiosa paradoja que estas remesas representaban: "mientras que la huida del capital de los sectores adinerados de la sociedad salvadoreña ha extraido muchos millones de dólares de la economía nacional, los sectores pobres han introducido nuevo capital al país" (1988, p. 26).

Estos estudios son importantes porque establecen la línea de base para entender la migración salvadoreña a los Estados Unidos. Para los científicos sociales, el altamente técnico reporte de Poitras es útil por los descriptores que revela (género, remesas, áreas de asentamiento, modo y punto de entrada a los Estados Unidos, duración de la estadía, deportabilidad, etc.). También llama la atención al movimiento humano a punto de empezar en Centroamérica en la década de los ochenta. Ocho años más tarde, Montes Mozo y García Vásquez, trabajando con datos obtenidos cuando la década está más avanzada, fueron los primeros académicos en ofrecer una perspectiva y comprensión más profundas de la huida masiva de salvadoreños a los Estados Unidos. La contribución de Montes Mozo y de García Vásquez fue más allá del trabajo académico al punto de suministrar documentación y asesoría a los miembros del Congreso de los Estados Unidos sobre asunto de refugiados salvadoreños durante el período de la guerra civil. Su investigación da un cuadro más exacto y suministra una útil compilación de datos, la combinación de información cuantitativa con análisis político.

20En total, el gobierno de los Estados Unidos contribuyó con \$3,500 millones en el esfuerzo bélico en El Salvador. 


\section{Salvadoreños en los Estados Unidos: el registro etnográfico}

Desde la década de los ochenta, los salvadoreños se establecieron en números significativos y formaron comunidades reconocibles en los Estados Unidos. El crecimiento y la significación de la diáspora salvadoreña se ha hecho evidente en el trabajo académico producido en la literatura de inmigración, en particular en las ciencias sociales. Se han escrito varias disertaciones sobre salvadoreños en los Estados Unidos desde que los trabajos de Poitras y Montes Mozo y García Vásquez fueran publicados en los ochenta (ver por ejemplo, Ward, 1987; Mahler, 1992; Menjívar, 1992; Repak, 1992; Zentgraf, 1998; Baker-Cristales, 1999; Landolt Marticorena, 2000; Hernández, 2002; Zilberg, 2002; Stowers, 2003; Rivas, 2007 y Kent, 2008). Algunas de ellas fueron más tarde publicadas como libros. En lo que sigue, discuto estos trabajos agrupándolos para propósitos comparativos. Si bien cada trabajo individual puede ser considerado en sí mismo, encontrar similitudes y diferencias ayudará a clarificar la experiencia salvadoreña en los Estados Unidos y los temas más relevantes que les afectan.

\subsection{Sirviendo, soñando y sobreviviendo en los Estados Unidos}

El primer grupo que discuto incluye cuatro etnografías publicadas entre 1995 y 2000: Waiting On Washington [Sirviendo a Washington] de Terry A. Repak $(1995)^{21}$; American Dreaming: Immigrant Life On The Margins [Sueño americano: vida inmigrante desde los márgenes] (1995) y Salvadorans in Suburbia: Symbiosis and Conflict [Salvadoreños en suburbia: simbiosis y conflicto] de Sarah J. Mahler (1995b) ${ }^{22}$; y Fragmented Ties: Salvadoran Immigrant Networks In America [Lazos fragmentados: redes inmigrantes salvadoreñas en Estados Unidos] de Cecilia Menjívar (2000) ${ }^{23}$. Cada autora se ocupó de una comunidad migrante salvadoreña específica dentro de la geografía de los Estados Unidos: Repak en Washington, D.C.; Mahler en el Long Island suburbano; y Menjívar en San Francisco.

El contexto de recepción de los inmigrantes en los Estados Unidos, como se explica más abajo, es la clave para entender estas etnografías. En Lazos fragmentados, Cecilia Menjívar postula un patrón configurado por el interjuego de tres fuerzas

21 Waiting On Washington se basa en la disertación doctoral de Repak, Mixed And Bitter Blessings: Migration Experiences Of Central Americans In Washington, D.C (1992).

22 Ambas etnografías tienen su origen en la disertación doctoral de Mahler Tres Veces Mojado: Undocumented Central And South American Migration To Suburban Long Island (1992). American Dreaming (1995a) es un trabajo más completo y significativamente más grueso comparado con Salvadorans In Suburbia (1995b). Otra característica que contrasta es que en American Dreaming, incluye dos grupos opuestos en busca de una nueva vida en el Long Island suburbano: los salvadoreños (en su mayoría de extracción rural, pobres y menos educados) y los peruanos, chilenos y colombianos (en su mayoría de clase media y trabajadora, de origen urbano y más educados). A pesar de las obvias diferencias, muchos de estos inmigrantes, si no la mayoría, eran indocumentados (1995a, pp. 17-25). Salvadorans In Suburbia (1995b) se enfoca enteramente en los salvadoreños; este volumen fue publicado como parte de la serie the New Immigrants, editada por Nancy Foner y publicada por Allyn y Bacon.

23Fragmented Ties: Salvadoran Immigrant Networks In America se basa en la disertación doctoral de Menjivar, Salvadorean Migration to The United States: The Dynamics of Social Networks in International Migration (1992). 
macro-estructurales que le dan forma a este contexto: "la política [migratoria] gubernamental, la economía local y la organización de la comunidad receptora” (2000, p. 77). En una lectura comparativa, la configuración de este patrón triádico, que se entrecruza con las redes sociales al darle forma a la estructura de las oportunidades socioeconómicas con las que los inmigrantes salvadoreños se encuentran en Estados Unidos, está presente de manera implícita en las etnografías de Repak y de Mahler; por tanto me parece útil examinarlas una junto a la otra. Un examen más cercano a cada etnografía revela diferencias substanciales en cómo estas fuerzas se configuran para crear los contextos de recepción. Los migrantes salvadoreños en Washington D.C encontraron el contexto de recepción más favorable; para los que llegaron a Long Island y San Francisco las tres dimensiones del contexto de recepción fueron desfavorables, lo cual explica las condiciones inhóspitas que hubieron de soportar.

Sirviendo a Washington de Terry A. Repak es un estudio del crecimiento gradual de una migración salvadoreña antes de la guerra civil, a la capital de Estados Unidos. Se basa en trabajo de campo que condujo entre 1988 y 1990, financiado por el Departamento de Trabajo de los Estados Unidos para examinar los efectos de IRCA sobre los mercados laborales en el área de Washington, D.C en negocios e inmigrantes. Repak estructuró sus hallazgos dependiendo principalmente de datos de encuesta recolectados en 100 hogares centroamericanos en Washington, D.C, y de entrevistas detalladas de historia de vida conducidas con 50 hombres y mujeres, en su mayoría salvadoreños ${ }^{24}$, a quienes conoció a través de tres agencias de servicios sociales (1995, pp. 197-201).

Sueño americano y Salvadoreños en suburbia de Sarah Mahler se basan en investigación etnográfica conducida entre principios de 1989 y finales de 1990 en varias comunidades suburbanas en los condados de Nassau y Suffolk en Long Island, New York. Mahler reunió sus datos localizando salvadoreños en ambos condados y entrevistando organizaciones que trabajan con ellos. El estudio se basa en una muestra de 350 cuestionarios anónimos, primordialmente de clases de inglés como segunda lengua; entrevistas con un número limitado de encuestados; entrevistas extensas e intensas con un grupo selecto de informantes cercanos que conoció a través de organizaciones comunitarias y por trabajar como voluntaria; y un estudio a profundidad de una comunida en la que ella vivió y trabajo durante seis meses (1995a, pp. 26-28).

Lazos fragmentados de Cecilia Menjívar es un estudio etnográfico de migrantes salvadoreños en el distrito de Mission District de San Francisco, basado en trabajo de campo hecho entre 1989 y 1991. Menjívar trabajó en varias organiaciones comunitarias locales donde reunió sus datos a traves de observaciones sistemáticas, una encuesta con 150 salvadoreños y entrevistas intensas con otros 50 (2000, pp. 12-21). La etnografía examina las interacciones personales, los intercambios y las redes sociales en las que los inmigrantes participan y construyen con el propósito de sobrevivir en Estados Unidos.

El estudio de Repak ofrece una importante perspectiva para comprender, a través de consideraciones basadas en la teoría de contratación laboral, que

24 La muestra entrevistada incluía algunos guatemaltecos y nicaragüenses; la muestra encuestada incluía guatemaltecos, hondureños, nicaragüenses y panameños (Repak, 1995, p. 38). 
las mujeres salvadoreñas lenta pero constantemente fueron las pioneras de la emigración a Estados Unidos en los años sesenta y setenta. Repak, enfocándose en patrones de contratación e inserción en el mercado laboral, revela que las mujeres salvadoreñas fueron directamente reclutadas/enganchadas y traidas directamente como empleadas domésticas y cuidadoras de niños por empleados profesionales, diplomáticos y gubernamentales de Washington en las dos décadas previas a la guerra civil. Con el paso de los años, las redes sociales provistas por las primeras migrantes salvadoreñas, el desarrollo de Washington hacia una "ciudad mundial" y el resultante auge económico que creó demanda de mano de obra no calificada, abrieron amplias oportunidades de trabajo para hombres salvadoreños en la construcción, la jardinería, los restaurantes, los hoteles y los servicios de aseo. Por tanto, Repak describe un contexto positivo de recepción, si bien su discusión sobre los efectos de IRCA revela un gobierno federal que intentaba manejar la inmigración por medio de controles legales más severos.

En contraste, el Sueño americano de Mahler ilustra un contexto de recepción mucho menos favorable, tal como lo indica la apertura de su etnografía: "[E]ste libro", anuncia sombriamente, "es una narrativa de la desilusión" (1995a, p. 3). De allí procede a presentar un relato de la desilusión con el así-llamado-y-ahoradifícil-de-alcanzar "Sueño Americano". En su trabajo de campo ella fue confrontada repetidamente con la falta de solidaridad étnica, lo que la llevó a cuestionarse el significado del concepto y su existencia en las comunidades que ella estudió. Teorías de incorporación económica de inmigrantes en un nuevo medio ambiente sostienen que, para tener éxito, la solidaridad étnica entre inmigrantes es crítica (1995a, pp. 10-13); el locus de esta solidaridad étnica está en la comunidad receptora tal y como se refleja en su organización. Confrontada por sus datos, Mahler se pregunta por qué había tanto "engaño, desazón, marginación y explotación" entre los inmigrantes indocumentados salvadoreños, peruanos, chilenos y colombianos que ella estudió. ¿Cuál fue la causa de estas desafortundas realidades y cómo se perpetuaron? (1995a, pp. $3-4$ y 13-14). Ella sugiere que estas maneras inescrupulosas de trato mutuo surgen del proceso de migración en sí, desde el principio hasta el final. Leyes migratorias restrictivas, particularmente IRCA, colocaron a los salvadoreños en una situación de marginación social y económica. Mahler considera que IRCA fue principalmente una condición agravante añadida a los problemas creados por los cambios económicos estructurales contemporáneos y la incapacidad de los inmigrantes para cumplir con sus demandas, es decir, falta de inglés, falta de destrezas para el mercado laboral y falta de credenciales. Todos estos factores socavan la posibilidad de crear el tipo de apoyo y de reciprocidad mutuos de familiares y compatriotas necesarios para que se den oportunidades de solidaridad étnica.

Como si la guerra civil no hubiera sido suficiente pesadilla para los salvadoreños pobres que huyeron para salvar sus vidas, Mahler ofrece una descripción sumamente perturbadora de los migrantes "intensamente alienados del Estados Unidos mayoritario y de sus instituciones" y enfocados en "su mutuo resentimiento" (1995a, p. 3). A lo largo de su etnografía ella muestra numerosas situaciones homo homini lupus, en las que aquellos migrantes que llegaron antes encuentran cualquier oportunidad para explotar económicamente a sus compatriotas más recientemente llegados con el fin de cubrir sus gastos diarios y sus obligaciones en El Salvador. 
Por otra parte, en Lazos fragmentados Menjívar indica que una característica de la literatura de migración ha sido identificar los lazos sociales que unen a los immigrantes y demostrar que estos lazos juegan un papel positivo y central en el proceso migratorio. Para los inmigrantes recientemente llegados, las redes informales de familiares y amigos en el lugar de destino idealmente proveen apoyo social, afectivo y económico que puede aminorar el impacto del desplazamiento; de ahí la atención que se da a las redes de inmigrantes. Sin embargo, ¿qué pasa cuando estas redes no funcionan de la manera como la teoría lo indica? En su estudio, Menjívar confirma que algunas de las expectativas usuales sobre redes sociales de migrantes fueron corroboradas, pero también se encontró con que las redes de inmigrantes salvadoreños no guardaban semejanza alguna con "extremadamente romantizadas nociones de unidad y solidaridad entre inmigrantes" (2000, p. 241). Ella revela que el conjunto de redes sociales informales entre los inmigrantes salvadoreños en San Francisco es fragmentado, frágil y dinámico antes que estable, cohesivo y estático. Menjívar se enfoca en las razones de la inestabilidad de estas redes, mostrando que "las redes sociales de inmigrantes no son inmumes a las condiciones físicas y materiales dentro de las que existen. Fuerzas macro-estructurales pueden servir para facilitar intercambios entre immigrantes y por tanto pueden contribuir a formar lazos duraderos pero también pueden impedir que la gente se ayude mutuamente" (2000, pp. 235-36).

En el proceso migratorio los migrantes dependen de redes y lazos sociales. Nuevas identidades sociales son creadas a través de la reconfiguración de redes sociales en respuesta a presiones de adaptación y a oportunidaes en la comunidad receptora; sin embargo, las nuevas identidades sociales creadas bajo estas circunstancias podrían no ser lo suficientemente fuertes como para sostener y reflejar las redes y los lazos sociales existentes en el país de origen. Además, Menjívar afirma en su etnografía que estas redes sociales se ven afectadas más que nada por el contexto de recepción en los Estados Unidos. Como resultado, ella sostiene que, "un contexto de recepción empobrecido, como el que se encuentra entre la mayoría de los salvadoreños, inhibe la capacidad de los inmigrantes para mantener normas de reciprocidad y normas de ayuda socialmente aceptadas e influye sobre el proceso a través del cual los immigrantes se ayudan mutuamente" (2000, p. 156).

En contraste con los hallazgos de Repak y más en línea con los de Mahler, Menjívar identifica y discute cómo la política migratoria estadounidense, la economía local y la organización de la comunidad receptora se configuran para crear un contexto desfavorable de recepción. Primero, el fallo de la la política migratoria estadounidense para conceder estatus de refugiado a los inmmigrantes salvadoreños, aunado con la aplicación de leyes migratorias cada vez más estrictas tales como IRCA, coloca a los inmigrantes salvadoreños en un perpetuo limbo legal, limitando así el acceso al empleo, la educación, la salud y otras oportunidades (Repak, 2000, pp. 80-89). Segundo, la difícil situación económica en San Francisco, agravada por la reacción violenta contra los inmigrantes en California a principios de los años noventa, significó que a los salvadoreños solamente se les ofrecieran trabajos inestables de baja remuneración, los cuales presentan poca oportunidad de ascenso social. Además, estas escasas oportunidades se redujeron substancialmente con la recesión de la década de los noventa. Esta situación disminuyó considerablemente 
las oportunidades de los inmigrantes salvadoreños para ayudarse mutuamente (Menjívar, 2000, pp. 89-109). Y tercero, varias organizaciones para refugiados se vieron delibitadas por la recesión económica y enfrentaron serios reveses para poder ayudar al mismo ritmo que en el pasado (2000, pp. 101-104). Además, familiares y amigos -que ahora carecían de los recursos necesarios para participar en intercambios mutuos- más que ser conductos de apoyo continuo e intercambio, demostraron haber debilitado e incluso ignorado los lazos que una vez fueran fuertes en El Salvador. Estos problemas fueron agravados por la evidente distancia social existente entre los nuevos inmigrantes salvadoreños y los antiguos residentes salvadoreños en el área, quienes diferían de los recién llegados en términos de clase social, estilo de vida e ideología política (2000, pp. 104-107).

Mientras Menjívar demuestra que la configuración específica de las tres fuerzas descritas arriba contribuye a la fragmentación de los lazos sociales y restringe las redes sociales. Ella también demuestra cómo el género y la edad afectan la interacción, específicamente en detrimento de las mujeres (2000, pp. 191-193), y cómo las diferencias generacionales son a veces modificadas de manera dramática por la inmigración: la generación mayor que ve su autoridad socavada por los hijos de la segunda generación o de la uno y medio -quienes a menudo actúan como intermediarios culturales-, se siente frustrada por la relación asimétrica entre la creciente responsabilidad y la falta de autonomía y respeto (2000, pp. 194-228). El género no es una nueva categoría analítica, la edad sí. Este análisis acerca del papel de las diferencias de edad agrega un substancial nivel de significación a la etnografía de Menjívar. En contraste, la investigación de Repak realza la importancía del género en la experiencia de inmigración al examinar cómo los roles de género de las mujeres y los hombres centroamericanos dentro de sus familias y hogares cambiaron como resultado del proceso migratorio (1995, pp. 159-176). Ella indica que las diferencias de género en los patrones de participación del mercado laboral eran notables en los datos que ella reunió. Las mujeres centroamericanas, que fueron las primeras en emigrar a la capital de Estados Unidos, se encontraron ganando mucho menos que su contraparte masculina en el mercado laboral. En contraste con las mujeres, los hombres disfrutaban un aumento de tres veces más salario en su trabajo actual que en su primer trabajo. En cambio, aun cuando las mujeres centroamericanas experimentaban autonomía y una independencia que les había sido negada en sus países, ellas experimentaban poca movilidad laboral o salarial, principalmente debida a factores estructurales, es decir, el limitado rango de ocupaciones disponibles para ellas y el que algunas veces estan confinadas a trabajos en el sector informal. No obstante, Repak argumenta que las teorías laborales existentes se quedan cortas para identificar o explicar las diferencias de género en las experiencias de hombres y de mujeres en el mercado laboral, en particular en cuanto a su movilidad económica (1995, pp. 116-122).

Las etnografías discutidas hasta este punto subrayan que efectivamente las redes sociales juegan un papel importante en el proceso migratorio y que, al mismo tiempo, la capacidad de las redes sociales migratorias no es fija. Puede variar a través del tiempo y bajo diferentes circunstancias. No se considera que las redes sociales puedan ser tranplastadas automáticamente a un nuevo territorio, el contexto de recepción, y que las fuerzas sociales más amplias que modifican este contexto, como 
se ha visto, tienen un efecto considerable sobre las redes sociales en sí y sobre la experiencia migratoria.

\subsection{La ley es una cosa, la justicia otra}

La política migratoria gubernamental, como se discutió en la sección anterior, es una de las fuerzas macro-estructurales que determina el contexto de recepción. En Legalizing Moves: Salvadoran Immigrants' Struggle For U.S. Residency [Movimientos legalizantes: La lucha de los salvadoreños por su residencia en los Estados Unidos] (Coutin, 2000), la autora coloca esta fuerza en primer plano. Coutin realizó su trabajo de campo entre 1995 y 1997, trabajando en agencias de inmigrantes en el área del Gran Los Ángeles que prestaban tutela legal a los salvadoreños. Ella estuvo presente en entrevistas con clientes migrantes salvadoreños, participó en una variedad de eventos (reuniones, sesiones de entrenamientos sobre leyes migratorias, manifestaciones, etc.) y asistió a audiencias en las cortes de migración. Además, entrevisto "un total de 90 organizadores comunitarios, proveedores de servicios legales y centroamericanos con casos de migración pendientes" (Coutin, 2000, pp. 19-20).

Coutin describe su trabajo como "una etnografía del proceso legal" más que una etnografía tradicional. El innovador enfoque de Coutin reside en su énfasis en el proceso legal más que en la descripción de migrantes salvadoreños específicos. El proceso legal que ella examina en su trabajo es el que los inmigrantes salvadoreños en los Estados Unidos tratan de seguir para obtener su estatus legal o definirse como legales; en la base de esta condición descansa la deficiente política migratoria estadounidense, tal y como es puesta en vigor por su cancerbero, la antigua INS, bizantina en sus procedimientos y kafkiana en sus categorías multiples, contradictorias y surrealistas de legalidad e ilegalidad. Coutin hábilmente ilustra las consecuencias concretas creadas por esta política de migración, experimentada por muchos inmigrantes salvadoreños como vivir en un estado legal de no-existencia (2000, pp. 23-25).

Las leyes de migración estadounidenses establecen serpenteantes límites de legalidad e ilegalidad, producen aquello a lo que Coutin se refiere como "espacios de no-existencia” (2000, pp. 29-34). Los migrantes salvadoreños indocumentados han sido consignados a un estatus ilegal que los ha reducido a vivir en estos espacios de noexistencia, de contradición entre su presencia física en los Estados Unidos y su falta de estatus legal. La no-existencia legal no impide su presencia física, participación social o activismo político, pero es una condición limitante que permea la vida diaria, desde los más pequeños y aparentemente más triviales eventos, tales como manejar u obtener una tarjeta para la biblioteca pública, a eventos relevantes en la vida, tales como enfermedad, deportación o muerte.

Coutin explora el impacto que las leyes de migración tienen sobre las vidas de los inmigrantes salvadoreños no como sujetos pasivos sino como agentes activos cuyos "movimientos" tienen un impactos sobre las posibilidades de legalizar su estatus desde el punto en que entran a Estados Unidos como inmigrantes indocumentados hasta el punto en que obtienen la legalidad o son deportados (2000, pp. 8-10 y 49-55). Su enfoque es hacer un relato de los esfuerzos de los 
inmigrantes mismos para legalizar su estatus mientras siguen viviendo en los Estados Unidos. En la descripción de esta lucha Coutin presenta cuán injusto, absurdo y obtuso es el sistema de ley migratoria; por ejemplo, "legalizarse requiere de obtener la documentación para la legalización, a la que sólo los documentados tienen fácil acceso" (2000, pp. 130-131). Por medio del cuidadoso empuje de los límites de la ley migratoria estadounidense, los inmigrantes salvadoreños pueden en muchos casos influenciar sus estipulaciones para su propia ventaja; es decir, al idear negociaciones y desafios a las interpretaciones del INS sobre la ley con respecto a su situación actual y a sus estrategias de legalización, ellos pueden bregar con los laberínticos procedimientos del INS.

Coutin también discute el papel de los defensores en organizaciones centroamericanas en el área del Gran Los Ángeles, quienes añaden una textura comunitaria al proceso. Estos juegan un papel importante como proveedores de tutela legal a su clientela salvadoreña en búsqueda de legalidad y de inclusión, situados como lo están entre sus clientes salvadoreños y la institución legal, y actuando "simultáneamente como agentes y críticos de la ley" (2000, p. 104). Consecuentemente, ellos acomodan las narrativas de sus clientes para conformarlas a códigos descontextualizados de linealidad, coherencia y temporalidad prescritos, a fin de argumentar efectivamente los casos de los inmigrantes mientras también critican la brec ha existente entre ley y justicia. "La ley es una cosas, la justicia otra", Coutin nos recuerda en el capítulo 4 (2000, p. 100).

La fuerza de la etnografía de Coutin deriva de su detallada descripción de la condición legal de los inmigrantes salvadoreños y de la posterior contextualización del continuo proceso de asentamiento de los salvadoreños en los Estados Unidos. En general, al enfocar su análisis en cómo lo legal engendra el criminalizante y categorizante estatus "ilegal", Coutin contribuye al entendimiento del impacto que la política migratoria estadounidense tiene sobre las vidas de los migrantes salvadoreños y provee un componente teórico clave para entender discusiones sobre transnacionalización, ciudadanía y legalidad a través del caso específico de El Salvador contemporáneo. Por otra parte, leer a Coutin junto a otros trabajos sobre legalidad versus ilegalidad -por ejemplo, el trabajo del 2005 de De Genova sobre migrantes mexicanos en Chicago-, da una perspectiva útil sobre este ejercicio, no sólo por el aspecto comparativo entre migrantes salvadoreños y mexicanos, sino por las maneras en que ambos trabajos ilustran cómo la política migratoria estadounidense toca todos los aspectos de la vida del inmigrante.

\subsection{Maneras de construir comunidad en una ciudad global}

A diferencia de los trabajos discutidos previamente, Seeking Community in a Global City: Guatemalans And Salvadorans In Los Angeles [Buscando comunidad en una ciudad global: Guatemaltecos y salvadoreños en Los Ángeles] de Nora Hamilton y Norma Stoltz Chinchilla (2001) ofrece una detallado relato de la historia de la migración centroamericana al sur de California (es decir, el área del Gran Los Ángeles) -particularmente de guatemaltecos y salvadoreños- apoyado en 20 años de trabajo de campo longitudinal que documenta la evolución de ambos grupos desde el principio de la migración a esta zona de California. El libro está basado 
en una variedad de métodos de recolección de datos: interacción continua con los miembros de las comunidades salvadoreña y guatemalteca; entrevistas con una amplia variedad de actores sociales que incluye refugiados, activistas, líderes comunitarios, proveedores de servicios, gente de negocios, organizadores laborales, profesores y líderes religiosos; investigación bibliográfica; y tres encuestas: la primera administrada en 1987-1988 a 83 pequeños negocios centroamericanos, la segunda conducida en 1989-1990 con trabajadores mexicanos y centroamericanos en el área del Gran Los Ángeles y la tercera como parte de un proyecto de investigación en San Francisco que involucró a 600 centroamericanos (2001, pp. 13-14).

El libro sigue un formato de narrativa progresiva, documentando la inmigración centroamericana al sur de California desde una amplia perspectiva. Por ejemplo, sucintamente esboza la historia de El Salvador y Guatemala; discute el contexto sociopolítico que provocó las olas masivas de refugiados empobrecidos que huyeron de la guerra civil y de la opresión política hacia el Gran Los Ángeles en los años ochenta, siguiendo los pequeños grupos de inmigrantes más de clase media en los años setenta quienes buscaban mejores oportunidades económicas. Prosigue a examinar detenidamente el contexto de recepción, el patrón de asentamiento, el desarrollo de las redes sociales guatemaltecas y salvadoreñas, y el establecimiento de vecindarios específicos, en particular de la comunidad centroamericana en Westlake en el centro de Los Ángeles. Las autoras ofrecen un excelente análisis que discute la entrada de los salvadoreños y los guatemaltecos a trabajos de bajo nivel y baja remuneración en los mercados laborales secundario e informal como trabajadores en la industria del vestido, personal de limpieza, trabajadoras domésticas, vendedores de la calle y jornaleros, y examina sus esfuerzos de organización: La United Needletrades, Industrial and Textile Employees (UNITE); la campaña Justice for Janitors; los esfuerzos por organizar a las trabjadoras domésticas bajo un programa patrocinado por la Coalition for Humane Immigrants' Rights of Los Angeles (CHIRLA); y los centros de vendedores de la calle y de jornaleros. También examinan un abanico de organizaciones políticas y de servicio social que sirven principalmente a salvadoreños y guatemaltecos: El Rescate, el Central American Refugee Center (CARECEN), el Central American Refugee Committee (CRECEN), Integración de Indigenas Mayas (IXIM), CHIRLA, el Comité en Solidaridad con el Pueblo de El Salvador (CISPES) y el Guatemalan Information Center (GIC). Se discute el período post-guerra civil de los años noventa, subrayando la creciente violencia que siguió durante esa década, la decisión resultante de muchos salvadoreños y guatemaltecos de quedarse en los Estados Unidos, y las nuevas formas de organización de la comunidad centroamericana en el Los Ángeles de la década de los noventa.

Si bien el libro junta a salvadoreños y guatemaltecos bajo el engañoso término de centroamericano, es ejemplo de un sólido y comprometido trabajo de investigación que se extiende por 20 años. La base teórica del libro aparece efectivamente integrada con el análisis de los resultados de las encuestas y la riqueza de las historias personales de los inmigrantes, colocando su análisis en el contexto del creciente racismo y sentimiento anti-inmigrante de la década de los noventa y más allá. 


\subsection{La transnacionalización de la migración salvadoreña}

Salvadoran Migration to Southern California: Redefining El Hermano Lejano [Migración salvadoreña al sur de California: Redefiniendo El Hermano Lejano] de Beth BakerCristales (2004) examina los lazos transnacionales entre los migrantes salvadoreños en Los Ángeles y su patria ${ }^{25}$. La investigación se realizó entre 1992 y 2001 en el sur de California y en El Salvador. Baker-Cristales fue voluntaria durante largos períodos de tiempo en organizaciones comunitarias, mientras vivía en el vecindario de Pico-Union, altamente poblado de migrantes salvadoreños. Ella visitó los pueblos saladoreños que más habían sido afectados por la emigración, participó en eventos comunitarios, se empapó de la cultura popular salvadoreña y condujo entrevistas formales con una amplia variedad de líderes comunitarios, emigrantes salvadoreños en los Estados Unidos, y migrantes de retorno y sus familiares en El Salvador (2004, pp. 6-11).

A diferencia de los trabajos discutidos previamente en este ensayo, la etnografía de Baker-Cristales busca esclarecer el flujo y reflujo de las formas culturales y de los discursos identitarios entre los salvadoreños en el sur de California y los que se quedaron en El Salvador. Al discutir una sesión de teleconferencia (la mejor tecnología disponible en ese entonces, antes que subsecuentes desarrollos tecnológicos hicieran las telecomunicaciones más simples, más baratas y más accesibles), ella propone la metáfora de la "mirada recíproca": "Los salvadoreños en ambos países sirven como la antítesis de memorias reconstruidas y como el fundamento de sueños no cumplidos" (Baker-Cristales, 2004, p. 48). Sin embargo, la mirada no garantiza exactitud, crea un fenómeno de distorsión transnacional: los migrantes salvadoreños idealizan un El Salvador ya desaparecido y sus familias en El Salvador idealizan un Estados Unidos lleno de promesas de éxito económico.

Más aún, ella explora la manera en la que el Estado salvadoreño ha respondido ambiguamente a sus ciudadanos que residen en Estados Unidos, a pesar de la dependencia económica en sus remesas. Su relato de la evolución y significado del discurso oficial sobre el hermano lejano aclara el entendimiento sobre este tema. Los capítulos en la etnografía de Baker-Cristales enfatizan las prácticas transnacionales de los migrantes salvadoreños, su relación con los gobiernos de los Estados Unidos y de El Salvador y sus relaciones con la gobernanza del Estado salvadoreño. Por medio de narrativas personales y otros datos etnográficos presentados en el libro es evidente que lejos de ser una entidad monolítica, "los salvadoreños en Los Ángeles no son un grupo claramente unido y cohesivo, lo cual hace que sus retratos etnográficos aparezcan como necesariamente fragmentados y parciales" (2004, p. 6). Inmigrantes de ambos bandos del espectro político salvadoreño salieron del país; cada lado tiene una perspectiva diferente de la guerra civil y de sus secuelas.

En los trabajos discutidos previamente, las autoras demuestran cómo la guerra civil salvadoreña, la economía local y la legislación migratoria estadounidense han configurado las vidas de los migrantes salvadoreños en los Estados Unidos; Baker-Cristales lleva la cuestión aún más lejos al explorar cómo estas fuerzas

25El libro es parte de la serie New World Diasporas publicada por la University Press of Florida y editada por Kevin A. Yelvington. 
macro-estructurales tienen también un impacto político y social en El Salvador. Su atención a instituciones estatales, formas legales de marginación y estructuras económicas evoca el análisis del postmodernismo como la lógica cultural ocasionada por regímenes de producción del capitalismo tardío propuesto por los académicos críticos Harvey (1990) y Jameson (1991). La contribución teórica más importante de esta etnografía proviene de la exploración del debate estatal y cómo es transformado por la reestructuración económica y política global. En lugar de postular la desaparición e irrelevancia del Estado tal y como lo conocemos, BakerCristales arguye que el Estado es transformado por la nueva economía política global (2004, pp. 20-30). Más aún, en el capítulo 4, la autora muestra cómo la gobernanza es transformada desde lo local a lo transnacional impactando las nociones de nacionalismo y culturas salvadoreños dentro y fuera del país, suministrando apoyo económico para las familias de los emigrantes y sus comunidades en El Salvador, participando en negocios transnacionales, promoviendo la mercantilización de la nostalgia por la patria y participando en la vida política transnacional, a pesar de no poder votar (2004, pp. 47-98). De muchas maneras el trabajo de Baker-Cristales hace una importante contribución para las teorías de la transformación del estado-nación en el capitalismo tardío tal como es discutido y significativamente desarrollado en el trabajo Nations Unbound: Transnational Projects, Postcolonial Predicaments, and Deterritorialized Nation-States [Naciones sin consolidar: proyectos transnacionales, situaciones postcoloniales y estados-naciones desterritorializados] de Basch, Glick Schiller y Szanton Blanc (1994).

El gobierno salvadoreño apoya la emigración de sus ciudadanos y anima a que se mantenga la economía de remesas; sin embargo, sigue reticente a otorgar el derecho al voto a los que residen en el extranjero. Este es un tema polémico en la política salvadoreña; necesitados por sus contribuciones para la economía salvadoreña, el entonces partido de derecha en el poder le temía y cortejaba a los migrantes salvadoreños. En consecuencia, Baker-Cristales señala que además del riesgo que supone el transnacionalismo de dejar a sus ciudadanos emigrantes en el limbo, este conlleva más explotación y somete a los migrantes al control de múltiples Estados (2004, pp. 120-125).

\section{Salvadoreños en los Estados Unidos: algunas conclusiones}

Los trabajos discutidos en este ensayo representan algunos de los más importantes trabajos académicos sobre salvadoreños en los Estados Unidos en los últimos 30 años. Es importante tener en mente que estos trabajos contribuyen a la literatura sobre migración internacional que trata sobre redes sociales de inmigrantes, política migratoria, estudios transnacionales, ciudadanía y estados-naciones en tiempos globales.

La guerra civil salvadoreña, que duró doce años, es el elemento histórico clave que precipitó el masivo éxodo salvadoreño hacia el Norte. Cada etnografía discutida incluye un capítulo de recuento de la guerra y de sus secuelas. En los Estados Unidos la visibilidad de El Salvador y de su conflicto armado siguió una 
ruta desde la cuasi-oscuridad (una "república bananera" en algún lugar en América Central) hasta una extensa cobertura en los medios de comunicación y luego convertirse en un tenue y casi olvidado recuerdo. No obstante, para los que migaron a los Estados Unidos y no han podido legalizar su situación migratoria, el calvario aún no ha terminado y todavía sufren las consecuencias de la ahora desacreditada ideología que obsesivamente guiara la política exterior estadounidense durante casi cinco décadas.

Un aspecto importante de la experiencia migratoria salvadoreña es la peligrosa jornada (usualmente por tierra) que los inmigrantes tienen que soportar de camino a los Estados Unidos. Mahler (1995a, pp. 58-82; 1995b, pp. 47-52) y Menjívar (2000, pp. 58-78) explícitamente discuten esta jornada como una experiencia transformadora para sus protagonistas; el resto de los autores aborda el tema de manera breve o implícita. Al final, esta tumultuosa historia revela que miles de personas fuera del país terminarían formando una comunidad salvadoreña reconocible en los Estados Unidos.

En las etnografías discutidas es evidente que los salvadoreños no son un grupo homogéneo ni social ni étnicamente a pesar de compartir un origen nacional común. Los migrantes salvadoreños discutidos en la etnografía de Mahler no podían ser más diferentes que los que aparecen en el trabajo de Repak; lo mismo se aplica para los migrantes que Menjívar estudió en San Francisco y los grupos más grandes y organizados en el área del Gran Los Ángeles estudiados por Coutin, Hamilton y Chinchilla, y Baker-Cristales. Asímismo, la solidaridad "étnica" automática no se da por sentada en la experiencia migratoria. Estas interacciones, como cada autor lo demuestra, están mediatizadas por factores como orígenes rurales versus urbanos, niveles de educación, edad, género, tendencias políticas y razones para dejar El Salvador. El ejemplo más terrible de cómo estos factores entran en juego es claramente ilustrado a lo largo del trabajo de Mahler, Sueño americano (1995). Menjívar (2000) ilustra una situación similar en Lazos fragmentados. Hamilton y Stoltz Chinchilla (2001) en Buscando comunidad apuntan a las tensiones existentes entre las organizaciones comunitarias salvadoreñas de diferentes orientaciones políticas. Finalmente, Baker-Cristales brega con las divisiones políticas entre diferentes organizaciones e individuos y con su dificultad para mantenerse políticamente neutra (2004, pp. 11-15).

Como se discutió más arriba, se calcula que casi la mitad de los salvadoreños en los Estados Unidos siguen indocumentados, hecho que los convierte en el mayor grupo nacional indocumentado en el país; es notable que los académicos no se hayan enfocado en esos individuos. Una etnografía que discuta salvadoreños que "lo lograron” en los Estados Unidos así como sus hijos nacidos en ese país queda por escribir.

Los trabajos etnográficos discutidos apuntan a dos importantes resultados precipitados por la experiencia migratoria en los Estados Unidos, combinados con fuerzas estructurales: el precario estatus legal que los salvadoreños todavía tienen que soportar a causa de las leyes migratorias estadounidenses y la masiva transnacionalización de El Salvador causada por la reestructuración política y económica global.

Las leyes migratorias estadounidenses uniformemente han impedido que 
justamente los salvadoreños logren el estatus de refugiados. Muchos años después de que la guerra civil terminara, estas políticas siguen en vigor, lo cual significa que un número alto de migrantes salvadoreños todavía siguen indocumentados, "viviendo en un estado de clandestinidad, en los márgenes de las regulaciones estatales" (Coutin, 2000, 2003). La falta de estatus legal o de documentos a corto plazo neutraliza su presencia física, los hace invisibles en Estados Unidos pero no en El Salvador. Los migrantes salvadoreños (con y sin documentos) "se han convertido en importantes actores políticos transnacionales, debido en gran parte a la creciente dependencia de El Salvador en las remesas de los inmigrantes" (Baker-Cristales, 2008). La diáspora salvadoreña ha mantenido vínculos económicos y culturales con su patria y los inmigrantes se han convertido en parte de la vida salvadoreña. En consecuencia, ellos juegan un importante papel en la constante transnacionalización de El Salvador.

Paradójicamente, los migrantes salvadoreños en los Estados Unidos constituyen una comunidad políticamente privada de sus derechos: no pueden participar en ninguna elección a menos que regresen a votar a su país, a pesar de las promesa de la administración del partido de derecha de cambiar esta situación. Por cierto, tampoco pueden participar de la vida política en Estados Unidos a menos que se hagan ciudadanos, lo que sólo unos pocos han logrado.

A excepción del estudio de 1988 de Montes Mozo y García Vásquez, el resto de trabajos discutidos están escritos en inglés y a la fecha no estaban traducidos al castellano. Existen varias etnografía escritas en castellano sobre inmigrantes salvadoreños en los Estados Unidos, estos trabajos tampoco han sido traducidos al inglés (ver por ejemplo, Sánchez Molina, 2005, 2006). Del mismo modo, la investigación sobre migración salvadoreña en general está dominada por estudios de salvadoreños en los Estados Unidos; poco se conoce de las comunidades salvadoreñas en otros países. La migración salvadoreña a los Estados Unidos a finales del siglo XX se entiende mejor como parte de los procesos contemporáneos de transnacionalización; por otro lado, la migración salvadoreña es parte de un assemblage social, político y cultural que incluye no sólo las formas e identificaciones culturales transnacionales de los migrantes sino una compleja telaraña de relaciones estatales, regulaciones y regímenes de observancia. Dada su naturaleza transnacional, esta situación crea un auténtico reto para el trabajo etnográfico. Si bien las etnografías tradicionalmente han tratado con grupos sociales a pequeña escala y en contextos específicos, la insuficiencia de estas nociones convencionales se revela cuando el lente de lo local apunta al complejo funcionamiento de fuerzas globalizantes mayores y cambio sistémico. Al conceptualizar la disciplina de esta manera se hace visible un nuevo conjunto de sitios etnográficos y de nodos para investigación en una variedad de contextos, por ejemplo, gubernamentales frente a no gubernamentales y narrativas oficiales frente a historias orales de redes transnacionales enraizadas en movimientos de solidaridad en tiempos de guerra en tanto que ellos le dieron forma a las rutas migratorias.

Hasta la fecha no existe ningún estudio unificador de los migrantes salvadoreños en los Estados Unidos. Cada etnógrafa enfatiza una región geográfica específica. Sería una contribución enorme para las ciencias sociales saber, por ejemplo, cómo les va a los salvadoreños en las áreas geográficas en las que se han 
concentrado con respecto a otros grupos y por qué, cómo les va en comparación a comunidades salvadoreñas menos visibles en otros lugares en Estados Unidos, en qué maneras son similares o diferentes a otros grupos de inmigrantes y qué tan útil es el concepto de transnacionalismo para entender su experiencia.

\section{Agradecimientos}

Agradezco a Jack Rollwagen por invitarme a contribuir en este número especial y por su paciencia, guía y apoyo durante el proceso de escritura. Agradecimientos especiales a los dos evaluadores anónimos, cuyos comentarios y sugerencias me ayudaron a mejorar la versión final de este artículo. Estoy en deuda con Peggy Seiden, jefe de biblioteca, y con todo el personal de McCabe Library, en Swarthmore College, por su fantástico apoyo durante todo el proceso. Ellas y ellos me acogieron en su biblioteca, me proporcionaron todos los recursos que necesitaba y, sobre todo, siempre tuvieron una amplia sonrisa y una palabra amable para mí. Finalmente quiero agradecer a Michael Ballagh, Roberta Camp, Betsy Morgan, Jim Stricks y Susan Phillips por su apoyo y amistad durante las fases del proceso de escritura. Todos los errores y omisiones son de mi total responsabilidad.

\section{Referencias bibliográficas}

Anderson, T. (1992). Matanza: The 1932 "Slaughter" that Traumatized a Nation: Shaping US-Salvadorean Policy to this Day. Willimantic, CT: Curbstone Press.

Australian Bureau of Statistics. (2009). 2006 Census Tables, Cat. No. 2068.0. Recuperado el 15 de octubre de 2009, de http://wwvv.abs.gov.auL.

Baker-Cristales, B. (1999). El Hermano Lejano: The Transnational Space of Salvadorean Migration to the US. Disertación Doctoral, Department of Anthropology, University of New Mexico.

Baker-Cristales, B. (2004). Salvadorean Migration to Southern California: Redefining el Hermano Lejano. Gainesville: University Press of Florida.

Baker-Cristales, B. (2008). Magical Pursuits: Legitimacy and Representation in a Transnational Political Field. American Anthropologist, 110 (3), 349-359.

Basch, L., Glick Schiller, N. \& Szanton Blanc, C. (1994). Nations Unbound: Transnational Projects, Postcolonial Predicaments, and Deterritorialized NationStates. Amsterdam: Gordon and Breach.

Basok, T. (1993). Keeping Heads Above Water: Salvadorean Refugees in Costa Rica. Montreal: McGill-Queen's University Press.

Booth, J., Christine, A., Wade, J. \& Walker, T. W. (2006). Understanding Central America: Global Forces, Rebellion, and Change. Boulder, Colorado: Westview Press.

Chávez, L. R. (1988). Settlers And Sojourners: The Case Of Mexicans In The US. Human Organization, (47), 95-108.

Córdova, C. B. (2005). The Salvadorean Americans. Westport, Conn.: Greenwood Press. 
Cornelius, W. (1992). From Sojourners to Settlers: The Changing Profile Of Mexican Immigration to Los Estados Unidos. En J. A. Bustamante, C. W. Reynolds, R. A. Hinojosa Ojeda (eds.). U.S.-Mexico Relations: Labor Market Interdependence. (pp. 155-195). Stanford, CA: Stanford University Press.

Coutin, S. B. (1995). Smugglers or Samaritans in Tucson, Arizona: Producing and Contesting Legal Truth. American Ethnologist 22 (3): 549-571.

Coutin, S. B. (2000). Legalizing Moves: Salvadorean Immigrants' Struggle for US. Residency. Ann Arbor: University of Michigan Press.

Coutin, S. B. (2003). Cultural Logics of Belonging and Movement: Naturalization, and U.S. Immigration Politics. American Ethnologist, 30(4): 508-526.

Coutin, S. B. (2007). Nations Of Emigrants: Shifting Boundaries of Citizenship In El Salvador And Los Estados Unidos. Ithaca: Cornell University Press.

Daniels, R. (1990). Coming to America: A History of Immigration and Ethnicity in American Life. New York: Harper Collins.

De Genova, N. (2005). Working the Boundaries: Race, Space, and "Illegality" in Mexican Chicago. Durham: Duke University Press.

Fuchs, L. \& Forbes, S. S. (1985). Immigration and U.S. History: The Evolution of the Open Society. En T. A. Aleinikoff \& D. A. Martin (eds.). Immigration Process and Policy. (pp. 38-59). St. Paul, Minn.: West Publishing Co.

García Vázquez, J. J. (1994). El impacto de las remesas en la estructura comunal y familiar. Un estudio de caso. En Konrad-AdenauerStiftung (edit.). Cultura y desarollo en El Salvador. pp. 292-321. San Salvador: Konrad-Adenauer Stiftung.

García Vázquez, J. J. (1996). Remesas y relaciones sociales locales. El caso de San Isidro. San Salvador: FLACSO Programa El Salvador.

Garland, S. (2009). Gangs In Garden City: How Immigration, Segregation, and Youth Violence Are Changing America's Suburbs. New York: Nation Books.

Gómez, I. \& Vásquez, M. (2001). Youth Gangs and Religion Among Salvadoreans in Washington and El Salvador. En A. Peterson, M. Vasquez \& P. Williams (eds.). Christianity, Social Change, And Globalization In The Americas. (pp. 165 187). New Brunswick, NJ: Rutgers University Press.

Haines, D. W. \& Rosemblum, K. E. (1999). Illegal Immigration in America: A Reference Handbook. Westport, CT: Greenwood Press.

Hamilton, N. \& Stoltz Chinchilla, N. (2001). Seeking Community in a Global City: Guatemalans and Salvadoreans in Los Angeles. Philadelphia: Temple University Press.

Harvey, D. (1990). Tile Condition of Postmodernity: An Enquiry into the Origins of Cultural Change. Cambridge, MA: Blackwell.

Hayden, B. A. (2003). Salvadoreans in Costa Rica: Displaced Lives. Tucson: University of Arizona Press.

Hernández, E. E. (2002). Power in Remittances: Remaking Family and Nation among Salvadoreans. Ph.D. Department of California, Irvine.

Jameson, F. (1991) Postmodernism, or, The Cultural Logic of Late Capitalism. Durham, NC: Duke University Press

Kent, S. (2008) Transnational Salvadoran Migration and the Consumption System: The Elucidation of Tensions, Inconsistencies, and Burdens. Disertación doctoral, Department of Anthropology, Michigan State University. 
Landolt, P. (2003). El transnacionalismo politico y el derecho al voto en el exterior: El caso de El Salvador y sus migrantes en Estados Unidos. En L. Calderón (ed.). Votar en la Distancia: La Extensi6n de derechos politicos a migrantes, experiencias comparadas. (pp. 301-323). Mexico, DF: Instituto de Investigaciones Dr. Jose Ma. Luis Mora.

Landolt, P., Autler, L. \& Baire, S. (1999). From Hermano Lejano to Hermano Mayor: The Dialectics Of Salvadorean Transnationalism. Ethnic and Racial Studies, 22(2), 290-315.

Landolt Marticorena, P. A. (2000). The Causes and Consequences of Transnational Migration: Salvadoreans In Los Angeles and Washington, D.C. Disertación doctoral, Department of Sociology, John Hopkins University.

Logan, J. R., Zhang, W. \& Alba, R. D. (2000). Immigrant Enclaves and Ethnic Communities in New York and Los Angeles. American Sociological Review, 67(2), 299-322.

Mahler, S. J. (1992). Tres Veces Mojado: Undocumented Central and South American Migration to Suburban Long Island. Disertación doctoral, Department of Anthropology, Columbia University.

Mahler, S. J. (1995a). American Dreaming: Immigrant Life On The Margins. Princeton, NJ: Princeton University Press.

Mahler, S. J. (1995b). Salvadoreans In Suburbia: Symbiosis And Conflict. Boston: Allyn and Bacon. The New Immigrants series.

Massey, D. S. (1987). The Ethnosurvey in Theory and Practice. International Migration Review, 21(4), 1498-1522.

Menjivar, C. (1992). Salvadorean Migration to The United States: The Dynamics of Social Networks in International Migration. Disertación doctoral, Department of Sociology, University Of California, Davis.

Menjívar, C. (1994). Salvadorian Migration to The United States in the 1980s: What Can We Learn About It and From It? International Migration, 32(3), 371-401.

Menjívar, C. (1999). Salvadoreans and Nicaraguans: Refugees Become Workers. En D. W. Haines \& K. E. Rosenblum (eds.). Illegal Immigration in America: A Reference Handbook. (pp. 232-256). Westport, Connecticut: Greenwood Press.

Menjívar, C. (2000). Fragmented Ties: Salvadorean Immigrant Networks in America. Berkeley: University of California Press.

Montes Mozo, S. \& García Vásquez, J. J. (1987). El Salvador 1987: Salvadoreños refugiados en los Estados Unidos. Instituto de Investigaciones, Universidad Centromericana (UCA): San Salvador.

Montes Mozo, S. \& García Vásquez, J. J. (1988). Salvadorean Migration to The United States: An Exploratory Study. Washington, DC: Hemispheric Migration Project, Center for Immigration Policy and Refugee Assistance, Georgetown University.

Morel, A. (1992). Refugiados salvadoreños en Nicaragua. Managua: ACRES.

Narváez Gutiérrez, J. C. (2002). Ruta transnacional: A San Salvador por Los Angeles: espacios de interaccion juvenil en un contexto migratorio. México: Universidad Autónoma de Zacatecas: Instituto Mexicano de la Juventud: Miguel Angel Porrua.

Palacio, J. O. (1985). Un medio rural para inmigrantes centroamericanos en Belice. 
Georgetown University, Washington, D.C.: Hemispheric Migration Project I Intergovernmental Committee for Migration.

Peterson, L. S. (1986). Central American Migration: Past and Present. Washington, DC: Center for International Research, U.S. Bureau of the Census.

Poitras, G. E. (1980a). International Migration to the United States from Costa Rica and El Salvador. San Antonio: Border Research Institute, Trinity University.

Poitras, G. E. (1980b). The United States Experience of Return Migrants from Costa Rica and El Salvador. San Antonio: Border Research Institute, Trinity University.

Population Reference Bureau. (2009). Data by Geography> EI Salvador> Population Trends. Recuperado el 15 de octubre de 2009, de http://www.prb.org/ Datafinder / Geography / Data.aspx?category=1O\& region=77\& region_ type $=2$.

Programa de las Naciones Unidas para el Desarrollo (PNUD). (2005). El Salvador 2005: las migraciones y el nuevo nosotros: versi6n popular ilustrada del Informe sobre desarrollo humano. San Salvador: Program a de las Naciones Unidas para el Desarrollo.

Programa de las Naciones Unidas para el Desarrollo (PNUD). (2006). Informe sobre el Desarrollo Humano 2005: una mirada al nuevo nosotros, el impacto de las migraciones. San Salvador: Programa de las Naciones Unidas para el Desarrollo.

Quizar, R. O. (1998). My Turn to Weep: Salvadorean Refugee Women in Costa Rica. Westport, CT: Bergin and Garvey.

Rader, V. (1999). Refugees at Risk: The Sanctuary Movement And Its Aftermath. En D. W. Haines \& K. E. Rosemblum (eds.). Illegal Immigration in America: A Reference Handbook. (pp. 325-345). Westport, CT: Greenwood Press.

Repak, T. A. (1992). Mixed and Bitter Blessings: Migration Experiences of Central Americans in Washington, D.C. Disertación doctoral, Department of Sociology, Emory University.

Repak, T. A. (1995). Waiting on Washington: Central American Workers in the Nation's Capital. Philadelphia: Temple University Press.

Restrepo, C. (2004). La población salvadorena en Estados Unidos. San Salvador: Serie de investigación. San Salvador: FUSADES. (Fundación Salvadoreña para el Desarrollo Económico y Social. Departamento de Estudios Económicos y Sociales).

Rivas, C. M. (2007). Imaginaries of Transnationalism: Media and Cultures of Consumption in El Salvador. Disertación doctoral, Department of Ethnic Studies, University of California, San Diego.

Rodríguez, A. P. (2009). "Departamento 15": Salvadorean Transnational Migration And Narration. En Dividing the Isthmus: Central American Transnational Histories, Literatures, And Cultures. (pp. 166-194). Austin: University of Texas Press.

Sánchez Molina, R. (2005). Mandar a traer: antropologia, migraciones y transnadonalismo. Salvadorenos en Washington. Madrid: Editorial Universitas,

Sánchez Molina, R. (2006). Proceso migratorio de una mujer salvadorefia: el viaje de María Reyes a Washington. Madrid: Centro de Investigaciones Sociológicas: Siglo XXI. Sermeño Lima, J. A. (1999). Medición e interpretación histórica de los movimientos internos de la población de El Salvador. Colección Aportes (6), San Salvador: FLACSO, Programa de El Salvador. 
Smith, B., Shue, S., Vest, J. L. \& Villarreal, J. (1999). Salvadoreans. En Philanthropy in Communities of Color (Philanthropic and Nonprofit Studies). (pp. 69-87). Bloomington: Indiana University Press.

Stanley, W. D. (1987). Economic Migrants or Refugees from Violence? A TimeSeries Analysis of Salvadorean Migration to the United States. Latin American Research Review, 22(1), 132-154.

Stowers, S. L. (2003). Hungry for the Taste of El Salvador: Gastronomic Nostalgia, Identity, and Resistance to Nutrithink in an Immigrant Community. Disertación doctoral, Department of Anthropology, University of Massachusetts at Amherst.

Vigil, J. D. (2002). A Rainbow of Gangs: Street Culture in the MegaCity. Austin, TX: The University of Texas Press.

Ward, T. W. (1987). The Price of Fear: Salvadorean Refugees in the City of the Angels. Disertación doctoral, Department of Anthropology, University of California, Los Angeles.

Waters M. C. \& Ueda, R. (2007). The New Americans: A Guide to Immigration Since 1965. Cambridge, MA: Harvard University Press.

Winschuh, T. (1999). ¿Por qué se van?: la emigración de Salvadoreños a los Estados Unidos. San Salvador: Ediciones Heinrich Boll.

Woodward, Jr. L. (1988). El Salvador. Oxford: Clio.

Wright, T. C. \& Moody, J. D. (2005). Salvadoreans. En J. Simich \& T. Wright (eds.). People of Las Vegas: One City, Many Faces. (pp.246-267). University of Nevada Press: Reno, Nevada.

Zentgraf, K. M. (1998). "I Came Only With My Soul": The Gendered Experiences of Salvadorean Women Immigrants in Los Angeles. Disertación doctoral, Department of Sociology, University of California, Los Angeles.

Zilberg, E. J. (2002). From Riots To A Spatial Cultural Politics Of Salvadorean Migration To And From Los Angeles. Disertación doctoral. Dissertation. Department of Anthropology, University of Texas at Austin.

Zilberg, E. J. (2004). Fools Banished from the Kingdom: Remapping Geographies of Gang Violence between the Americas (Los Angeles and San Salvador). American Quarterly, 56(3), 759-779.

Zilberg, E. J. (2007). Refugee Gang Youth: Zero Tolerance and the Security State in Contemporary U.S.Salvadorean Relations. En S. Venkatesh \& R. Kassimir (eds.). Youth, Globalization, and the Law. (pp. 61-89). Stanford: Stanford University Press. 